\title{
Mineral Preparation in Geological Research
}

\author{
T. Yusupov ${ }^{(\bowtie)}$, A. Travin, S. Novikova, and D. Yudin \\ V.S. Sobolev Institute of Geology and Mineralogy SB RAS, Novosibirsk, Russia \\ yusupov@igm.nsc.ru
}

\begin{abstract}
Paper deals with discussion of minerals' preparation requiring high purity monoproducts, this has special importance for minerals -geochronometers. Widely used methods including gravitation, magnetic separation, floatation provide fractions with $90 \%$ of targeted mineral. Further monominerality increase requires special separation methods; one of them - "Strat" is perspective. It is based on separation in organic liquids under gradual density change. Combination of bromoform with $\mathrm{d}-2.89 \mathrm{~g} / \mathrm{sm}^{3}$ and dimethyle formamide with $\mathrm{d}-$ $0.8 \mathrm{~g} / \mathrm{sm}^{3}$ is used; density gradations till $0.001 \mathrm{~g} / \mathrm{sm}^{3}$ are possible therefore isomorphic inclusions could be separated. Another direction is presented by trybotreatments under higher energies in planetary mills with a centrifugal factor to $40-50 \mathrm{~g}$. Exotic surface substances presented mainly by kaolinite, muscovite, calcite, gothite are removed as trybotreatment result. Special planetary mills classifiers are used for processing of big samples. This method together with minerals opening in disintegrator under destruction by the free pulse is recommended for wide application.
\end{abstract}

Keywords: Monominerality $\cdot$ Geo chronometers $\cdot$ Separation $\cdot$ Surface • Organic liquids $\cdot$ Trybotreatment

\section{Introduction}

Many mineralogical and geochemical researches are based on mono mineral products' studies; acquisition of these products is based on research intensive processes of minerals' revealing and extracting. This assumption is relevant to geochemical, geophysical, lithologic, petrochemical and other studies; geochronological definitions became wider during recent years.

The task to extract minerals - chronometers of mono mineral purity is very important and complicated. The problem becomes much more complicated when chronometers are extracted from geo objects which have precious and rare metal character. This happens due to their very low content, thin dispersion and occurrence in genetic association (intergrowth) with usually rock-forming minerals.

Range of rock-forming and ore minerals which are used for rock dating is widening. Analysis is concentrated on such minerals as plagioclases, olivine, ortho and clino pyroxene, phlogopite, tourmaline, sphalerite, volframite, tin spar, pyrite, pyrrhotite, pentlandite and others. Special methods should be developed for the extraction of many of these minerals (Isotope..., 2015; Methods..., 2018). 


\section{Methods, Approaches, Results and Discussion}

We develop new section in sample preparation - mineral preparation, which includes number of new research and methodological aspects.

1. Preliminary concentrating of minerals - chronometers from objects with very low their content. Only intermediate products which are used for mono mineral fractions extraction could be obtained by traditional types of separation - gravity, magnet and floating.

Gravitation methods are helpfully used in the situations where differences between density of extracted mineral and monaural basis are not lower than $3 \mathrm{~kg}$ per sm $\mathrm{sm}^{3}$. Losses of target mineral are significant under other combinations of densities. Magnet methods are more effective when differences in magnet sensitivity of separating components are sufficient for separation. This is true for the case of quartz from -0.40 to 0.10 and biotite from +46.7 to $86.7109 \mathrm{~m}^{3} / \mathrm{g}$. Under lower differences in magnet sensitivity of minerals which are contained in samples at the level of accessory units extraction is extremely difficult.

Great perspectives in the extraction of minerals from extremely poor subsurface rocks are related with floatation process which makes it possible to get minerals with less than $0.1 \%$ content in sample. Obtained products of preliminary concentration should either be further grinded in order to open intergrowths or be dressed with the help of special concentrating methods till mono mineral state. Combine schemes with mono mineral and similar products extractions at the initial stage are often used; then intergrowths minerals opening and repeated concentrating of targeted minerals take place (Berger 1962).

2. Opening of minerals from intergrowth stage done with the help of mechanical treatments may be accompanied by significant structural chemical changes. It is necessary to avoid high temperatures, local high pressures and if possible to use dry process. High energetic free pulse realized in desintegrators is effective method of minerals - chronometers' opening. Prospectivity of desintegrator's use for ore preparation is proved on the cases of different minerals: spodumene, apatite, sulfides and others. Higher preservation of crystal structure and lower over grinding are considered to be main advantages here (Yusupov et al. 2015). Positive aspects of mineral preparation were revealed under disintegrating of quartz - feldspar associations (Yusupov et al. 2018). Disintegrated sample preparation is recommended for wide use.

3. Obtained concentrates were dressed by methods of mono mineral fractions extraction with extraction of products with $90 \%$ of targeted mineral (Methods... 1985). Further increase of mono mineral character is reached by the help of special methods. Gradual separation in organic liquids on density - "Starts" method and trybo treatment - surface attrition under higher energies of mechanical treatment are wide used. Mixture of bromform with $\mathrm{d}-2.89 \mathrm{~g} / \mathrm{sm}^{3}$ and dimethyle formamide with $\mathrm{d}-0.8 \mathrm{~g} / \mathrm{sm}^{3}$ is used as separation media. Different density gradations till $0.001 \mathrm{~g} / \mathrm{sm}^{3}$ are possible here. Potential of the method is shown on the example of quartz - feldspar associations with $-0.3+0.2 \mathrm{~mm}$ size (Table 1). 
Table 1. Reparability of minerals of non electromagnetic quartz feldspar product

\begin{tabular}{l|l|l|l|l|l|l|l|}
\hline Fraction density $\mathrm{g} / \mathrm{sm}^{3}$ & Output, \% & \multicolumn{7}{|l}{ Elements content, \% } \\
\hline & & $\mathrm{SiO}_{2}$ & $\mathrm{Fe}_{2} \mathrm{O}_{3}$ & $\mathrm{Al}_{2} \mathrm{O}_{3}$ & $\mathrm{~K}_{2} \mathrm{O}$ & $\mathrm{Na}_{2} \mathrm{O}$ & $\mathrm{Li}_{2} \mathrm{O}$ \\
\hline Initial & & 81.1 & 0.03 & 12.3 & 2.48 & 5.18 & 0.028 \\
\hline $2.44-2.55$ & 7.881 & 65.3 & 0.02 & 19.3 & 13.3 & 1.28 & 0.097 \\
\hline $2.55-2.58$ & 3.751 & & & & & & \\
\hline $2.58-2.61$ & 5.109 & & & & & & \\
\hline $2.61-2.63$ & 43.795 & 71.0 & 0.03 & 18.4 & 0.51 & 9.82 & 0.004 \\
\hline $2.63-2.65$ & 35.737 & 98.7 & 0.03 & 1.4 & 0.12 & 0.62 & 0.017 \\
\hline
\end{tabular}

Potassic feldspar product with $7.88 \%$ output was extracted under $2.44-2.55 \mathrm{~g} / \mathrm{sm}^{3}$ density. Fraction of sodium feldspar is concentrated under higher density $\mathrm{d}-2.61-$ $2.63 \mathrm{~g} / \mathrm{sm}^{3}$ with output of $43.79 \%$. Density of quartz fraction is more close to similar indicator for sodium spar with density interval being $2.63-2.65 \mathrm{~g} / \mathrm{sm}^{3}$ and output $35.73 \%$.

These results confirm high effectiveness of density method; separation of $0.05 \mathrm{~mm}$ and lower size products looks possible (Yusupov et al. 2015). Method is successfully used for not only quartz and feldspar separation but also for muscovite, biotite, glauconite (Katz 1977).

Trybo attrition impacts are under investigated though they are important for mineral's homogeneity increase. They enable to remove inclusions of tramp substances presented mainly by kaolinite, muscovite, calcite, gothite as well as by remaining floating reagents.

It is important to take into account that after removal of surface layers of $0.1-10$ mcm thickness surface is characterized by different structural imperfections. They could vary from practically unchanged state to totally crystal and chemically destroyed surface (Yusupov et al. 2018).

Trybo treatment looks as important way to increase mono mineral character. Hand attrition in jet and jasper stamps is widely used in institute's analytical practice. Method is applied for treatment of biotite, glauconite, amphibolites, tourmolin spinels, phosphates, sulphides and other minerals with monomimeral coefficients being about $100 \%$.

Facilities of PMK type are effective for large samples with weight more than $1 \mathrm{~kg}$ trybo treatment. Material here is exposed by planetary rotating movement of ore mass. Such technological regime selectively destroys impurity substances and increases monomineral properties of extracting products. Improved version of this mechanism is being developed at CJSC "Itomak", Novosibirsk.

Trybotreatment not only removes impurity substances but also changes surface defectiveness character and mineral heterogeneity type. Heterogeneity management is under investigated methodologically however its role in ores processing is constantly growing. For example concentrate with $0.05 \%$ ferrous oxide was got from quarts with $1.5 \%$ of this component. This result could not be reached by other methods. It is important to provide transfer to homogeneous state when minerals have similar character of structural defects. Type and level of trybo treatment make it possible to solve these problems to certain extent. 


\section{Conclusions}

Methodical bases of samples preparation in processes of mineral products extraction are reviewed. Taking into account orientation of these methods it is suggested to name this approach mineral preparation.

Possibilities of minerals separation by "Strat" method which is based on use of organic liquids with different density and surface trybo treatment are discussed. Mono mineral products of high quality are obtained as a result of methods application.

These methods as well as disintegrated minerals opening are recommended for wide application in analytical practice.

\section{References}

Berger GS (1962) Minerals' floatating. Gortechizdat, Moscow

Ginzburg AI (1985) Mineral research methods Nedra, Moscow

Isotope dating of geological processes: new results, approaches and perspectives (2015) VI

Russian conference in isotope geochronology. IPGG RAS, Saint Petersburg

Katz MY (1977) Minerals' heterogeneity analysis. Nauka, Moscow

Methods and geo chronological results of isotope geometric minerals systems and ores studies (2018) VII Russian conference in isotope geochronology, Moscow

Yusupov TS, Baksheeva II, Rostovtsev VI (2015) Analysis of different-type mechanical effects on selectivity of mineral dissociation. J MiningSci 51:1248-1253

Yusupov TS, Travin AV, Yudin DS, Novikova SA, Shumskaya LG, Kirillova EA (2018) Improvement of methods of minerals - geo chronometers extraction from ores for geological processes isotope dating. In: Shchiptsov VV (ed.) Fundamental and applied aspects of technologica lmineralogy, Petrozavodsk. Russian conference in isotope geochronology, pp 86-92

Open Access This chapter is licensed under the terms of the Creative Commons Attribution 4.0 International License (http://creativecommons.org/licenses/by/4.0/), which permits use, sharing, adaptation, distribution and reproduction in any medium or format, as long as you give appropriate credit to the original author(s) and the source, provide a link to the Creative Commons license and indicate if changes were made.

The images or other third party material in this chapter are included in the chapter's Creative Commons license, unless indicated otherwise in a credit line to the material. If material is not included in the chapter's Creative Commons license and your intended use is not permitted by statutory regulation or exceeds the permitted use, you will need to obtain permission directly from the copyright holder.

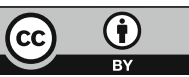

